DOI 10.37882/2223-2982.2021.12-2.19

\title{
ИНФОРМАЦИОННАЯ СИСТЕМА ПО ИЗУЧЕНИЮ МЕХАНИЧЕСКОЙ УСТОЙЧИВОСТИ, АВАРИЙНОСТИ И ЭКОЛОГО-БИОЛОГИЧЕСКИХ ОСОБЕННОСТЕЙ ОСНОВНЫХ ВИДОВ ДРЕВЕСНЫХ РАСТЕНИЙ, ИСПОЛЬЗУЕМЫХ В ОЗЕЛЕНЕНИИ ГОРОДА ДОНЕЦКА, КАК СРЕДСТВО ФОРМИРОВАНИЯ ПРЕДМЕТНЫХ КОМПЕТЕНЦИЙ В ШКОЛЬНОМ КУРСЕ БИОЛОГИИ
}

\section{INFORMATION SYSTEM FOR THE STUDY OF MECHANICAL STABILITY, ACCIDENT RATE, ECOLOGICAL AND BIOLOGICAL FEATURES OF THE MAIN TYPES OF WOODY PLANTS USED IN THE LANDSCAPING OF THE DONETSK CITY, AS THE MEANS OF ESTABLISHMENT OF SUBJECT COMPETENCIES IN SCHOOL BIOLOGY COURSE}

\section{Kornienko \\ K. Avdeeva \\ A. Yaitsky}

Summary: The article deals with the ways of forming subject competencies in biology, through an information system which studies mechanical stability, accident rate and ecological and biological features of the main types of woody plants used in the landscaping of the Donetsk city. Information system which was developed contains visual generalized structured material on mechanical stability, accident rate, ecological and biological features of the main types of woody plants used in landscaping of the Donetsk city. Usage of this information system during biology classes forms the main subject competencies of students.

Keywords: competencies, subject competencies, information system, database, biology, extracurricular work, laboratory work.

\section{Введение}

В настоящее время достижения в области биологических наук свидетельствуют о том, что они занимают ключевые позиции в медицине, здравоохранении, гигиене, охране окружающей среды, обеспечении населения продуктами питания, лекарственными средствами. Ввиду этого представляется необходимым формирование и развитие биологической грамотности населения. Именно школьная дисциплина «Биология» является важным звеном в формировании у учащихся биологической картины мира, экологической культуры, аксиологического
Корниенко Владимир Олегович Старший преподаватель, ГОУ ВПО «Донецкий национальный университет»

kornienkovo@mail.ru

Авдеева Ксения Александровна

ГОУВПО «Донецкий начиональный университет» kseniaavdeeva13@gmail.com

яицкий Андрей Степанович

Старший преподаватель, ФГБОУ ВО «Самарский государственный сочиально-педагогический университет» yaitsky@sgspu.ru

Аннотация: В статье рассматривается вопрос о формировании предметных компетенций по биологии посредством информационной системы по изучению механической устойчивости, аварийности и эколого-биологических особенностей основных видов древесных растений, используемых в озеленении города Донецка. Разработанная информационная система содержит наглядный, обобщенный, структурированный материал по механической устойчивости, аварийности и эколого-биологическим особенностям основных видов древесных растений, используемых в озеленении города. В результате использования данной информационной системы в процессе обучения биологии, у учащихся формируются основные предметные компетенции по биологии.

Ключевые слова: компетенции, предметные компетенции, информационная система, база данных, биология, лабораторная работа, внеклассная работа.

взгляда на природу и общество, в осознании своей роли как действенного фактора биосферы.

В условиях активного развития информационного общества, для дальнейшего прогресса в условиях возрастающей глобальной конкуренции, наиболее важными факторами конкурентоспособности являются квалифицированные человеческие ресурсы и научная база. Одним из приоритетных становится такое понятие как «компетенция».

Общепринятого определения понятия «компетен- 
ция» не существует. По мнению А.В. Хуторского, «компетенция» - «отчужденное, заранее заданное социальное требование к образовательной подготовке ученика, необходимой для его эффективной продуктивной деятельности в определенной сфере» [1]. В.С. Леднев, Н.Д. Никандров, М.В. Рыжаков выражают мнение, что «компетенция является <...> сферой отношений, существующих между знанием и действием в человеческой практике» [2]. В школьных условиях под компетенцией понимается «готовность учащихся самостоятельно действовать в ситуациях неопределенности при решении актуальных для них задач теоретического и прикладного значения» [3].

Формированию компетенций для повседневной жизни и для общего развития, а также общей функциональной грамотности способствует базовое изучение школьных дисциплин, в то время как результаты углубленного изучения ориентированы на приобретение компетенций для последующей профессиональной деятельности как в рамках данной предметной области, так и в смежных с ней сферах [4]. Таким образом, при углубленном изучении какой-либо учебной дисциплины у учащегося формируются предметные компетенции.

Предметные компетенции - это специфические способности, необходимые для эффективного выполнения конкретного действия в конкретной предметной области и включающие узкоспециальные знания, особого рода предметные умения, навыки, способы мышления [5]. Формирование предметной компетенции только тогда является успешным, когда оно постоянно реализуется в учебной и практической деятельности.

Целью нашей работы стало исследование возможности применения информационной системы по изучению механической устойчивости, аварийности и экологобиологических особенностей основных видов древесных растений, используемых в озеленении города Донецка, для формирования предметных компетенций по биологии.

\section{Материалы и методы}

Для достижения поставленной цели была взята информационная система по изучению механической устойчивости, аварийности и эколого-биологических особенностей основных видов древесных растений, используемых в озеленении г. Донецка, которая применяется в мониторинговых исследованиях состояния окружающей среды в городе [6]. Выбирая систему, мы ориентировались на такие критерии как простота использования и доступность для учащихся.

\section{Описание информашионной системы}

Информационная система по изучению механиче- ской устойчивости, аварийности и эколого-биологических особенностей основных видов древесных растений [7] содержит 18 разделов, в которых описаны виды древесных растений: «Acer negundo L.», «Acer platanoides L.», "Acer pseudoplatanus L.», "Acer saccharinum L.», "Aesculus hippocastanum L.», «Betula pendula Roth», «Fraxinus pennsylvanica Marsh.», «Fraxinus excelsior L.», «Robinia pseudoacacia L.», «Gleditsia triacanthos L.», «Morus alba L.», «Populus bolleana Lauche», «Populus simonii Carriere», "Populus nigra L.», "Quercus robur L.», "Quercus rubra L.», «Tilia cordata Mill.», «Ulmus laevis Pall.», а также раздел «Авторы».

На титульной странице содержится информация о результатах исследований устойчивости основных видов, используемых в озеленении города Донецка, к действию механических факторов природного и антропогенного происхождения (рис. 1).

В каждом разделе есть подразделы, которые описывают систематическое положение вида, биологию и экологию, биогеографию, представленность в условиях города, механическую устойчивость и аварийность вида, ветроустойчивость, корневую систему, критический возраст, наличие спила/керна в ксилотеке, рекомендации для озеленителей, публикации о виде, его фотографии.

В подразделе «Биология и экология», например, для клена ложноплатанового (Acer pseudoplatanus L.) дано краткое описание вида с особенностями произрастания в городе Донецке (рис. 2).

В подразделе «Биогеография» указан естественный ареал распространения растения, в подразделе «Представленность в условиях города Донецка» информация приведена согласно данным, собранным в период с 2014 по 2019 гг. В подразделе «Механическая устойчивость и аварийность» приведены экспериментальные данные по физико-механическим свойствам живой древесины, а также степень аварийности растений в условиях города Донецка (рис. 3).

«Критический возраст в условиях города Донецка» приведен для каждого вида и основывается на результатах исследований. Сведения об устойчивости древесных растений представлены в разделах «Ветроустойчивость» и «Корневая система».

\section{Реализашия информашионной системы в образовательной среде}

В условиях среднего общего образования Донецкой Народной Республики, опробование информационной системы возможно в 6 классе при изучении темы «Растения. Бактерии. Грибы. Лишайники». Согласно примерной основной образовательной программе, на изучение 


\section{База данных}

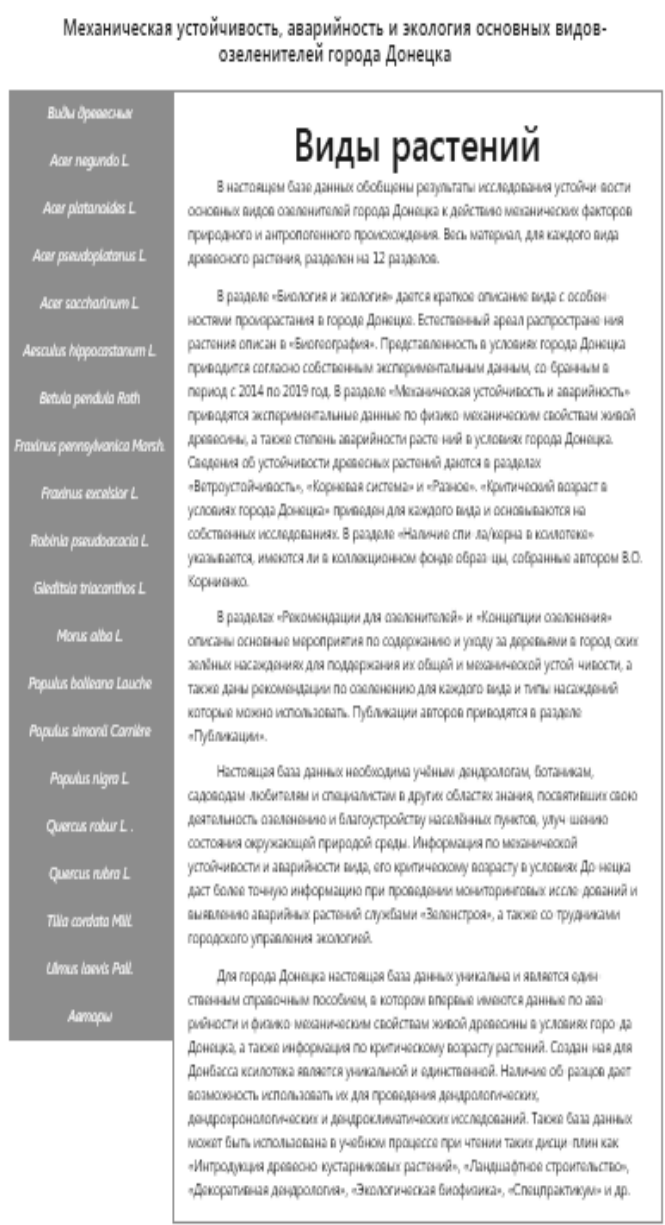

Рис. 1. Титульная страница базы данных по механической устойчивости, аварийности и экологии основных видов-озеленителей города Донецка

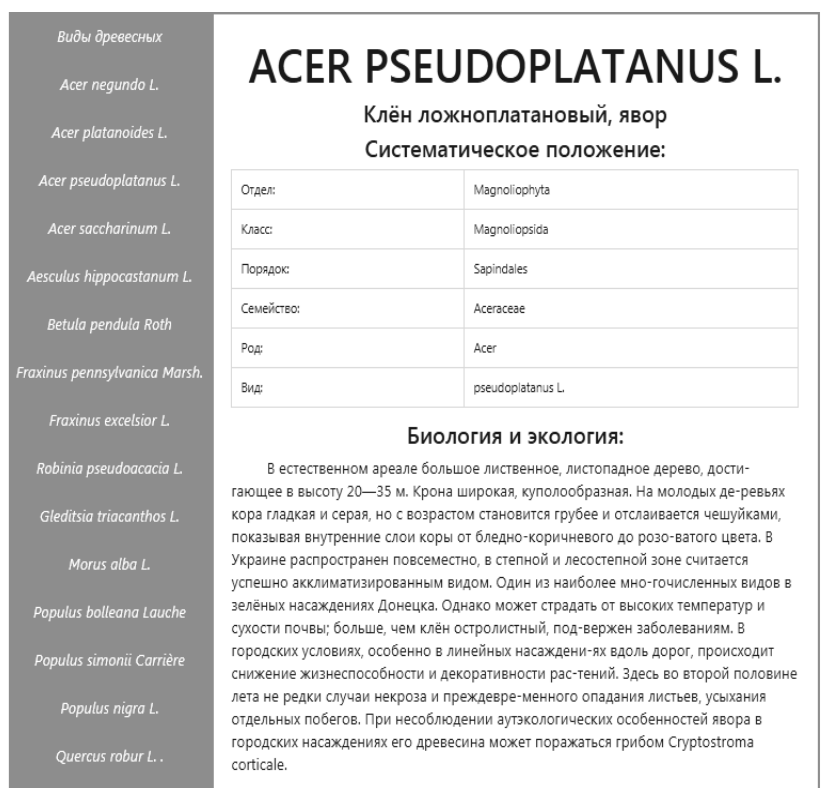

Рис. 2. Подраздел «Биология и экология» 


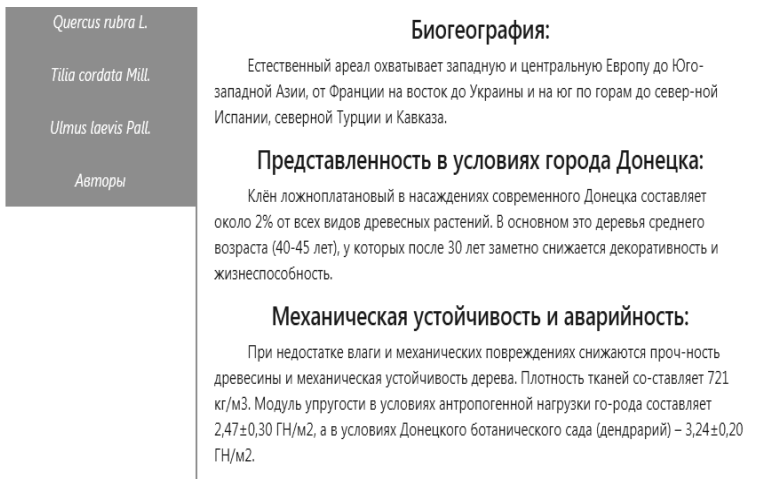

Рис. 3. Подразделы «Биогеография», «Представленность в условиях города Донецка», «Механическая устойчивость и аварийность»

Таблица 1.

Учебно-тематическое планирование по биологии в 6 классе

\begin{tabular}{|c|c|c|}
\hline Тема & Общее количество часов & Количество лабораторных и практических работ \\
\hline Введение & 1 & - \\
\hline Тема 1. Клетка - основа строения и жизнедеятельности организма & 2 & 1 \\
\hline Тема 2. Многообразие организмов & 1 & - \\
\hline Тема 3. Органы цветкового растения. Жизнедеятельность цветковых растений & 7 & 2 \\
\hline Тема 4. Генеративные органы. Половое размножение растений & 5 & 1 \\
\hline Тема 5. Низшие и высшие споровые растения & 5 & 1 \\
\hline Тема 6. Семенные растения & 8 & 1 \\
\hline Тема 7. Грибы, лишайники & 3 & - \\
\hline Резерв & 3 & - \\
\hline Bсего: & 35 & 6 \\
\hline
\end{tabular}

биологии в 6 классе отводится 35 часов (1 ч. в неделю), резерв 3 ч. Учебно-тематическое планирование дисциплины для 6 класса представлено в табл. 1.

Материалы информационной системы по механической устойчивости, аварийности и экологии основных видов-озеленителей города Донецка [7] были внедрены в учебный процесс средних общеобразовательных школ № 118 г. Донецка и № 46 г. Макеевка и использовались при освоении темы «Семенные растения». Были разработаны и организованы лабораторная работа «Определение видов древесных растений по плотности древесины» и внеклассное мероприятие на тему «Озеленение пришкольного участка».

\section{Лабораторная работа}

Тема: «Определение видов древесных растений по плотности древесины».

Цель работы: формирование у учащихся умений измерять плотность древесины в лабораторных условиях и, на основании полученных результатов, определять виды древесных растений.
Оборудование и принадлежности: свежесрезанные образцы (керны и спилы клена ложноплатанового, клена ясенелистного, ясеня обыкновенного, шелковицы белой и липы мелколистной), весы, мерный цилиндр с водой.

\section{Теоретическая часть}

Древесина - основная часть древесного ствола (плотный, самый широкий слой, лежащий под корой). Состоит из клеток проводящей ткани (сосуды), механической ткани (волокна), основной ткани. Строение древесины зависит от температурно-влажностных условий роста и объёма поступающих питательных веществ.

Виды древесных растений можно определить, зная плотность их древесины. Плотностью тела называется физическая величина, которая измеряется отношением массы тела к его объёму.

\section{Ход работы}

1. Определить массу образца древесины с помощью весов.

2. По закону Архимеда определить объём образца древесины (рис. 4). Для этого заполняем цилиндр 
водой до отметки 20 ед. Помещаем образец в цилиндр с водой и считаем разность $\Delta \mathrm{V}$ по формуле: $\Delta \mathrm{V}=\mathrm{V}_{2}-\mathrm{V}_{1} ; \Delta \mathrm{V}={ }_{\text {уобразца }}$.

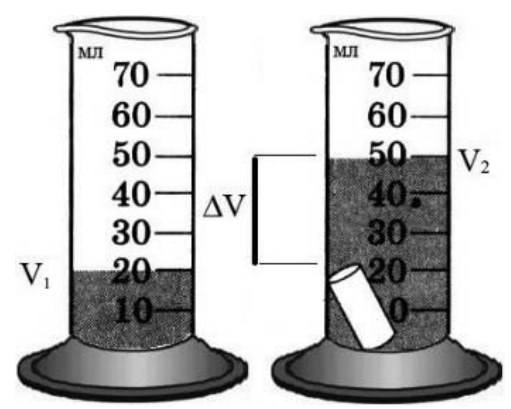

Рис. 4. Схема определения объёма образца древесины

3. Вычислить плотность образца древесины по формуле:

$$
\rho=m / V_{\text {образца }} \text {. }
$$

4. Определить плотность древесины всех образцов.

5. Провести идентификацию согласно информационной системе.

6. Все данные занести в таблицу (табл. 2).

Определение видов древесных растений по показателю плотности древесины

\begin{tabular}{|c|c|c|c|c|}
\hline $\begin{array}{c}\text { № } \\
\text { п/п }\end{array}$ & $\begin{array}{c}\text { Масса } \\
\text { образца, кг }\end{array}$ & $\begin{array}{c}\text { Объём } \\
\text { образца, } \mathrm{M}^{3}\end{array}$ & $\begin{array}{c}\text { Плотность } \\
\text { образца, кг/м³ }\end{array}$ & $\begin{array}{c}\text { Виды древесных } \\
\text { растений }\end{array}$ \\
\hline & & & & \\
\hline & & & & \\
\hline & & & & \\
\hline
\end{tabular}

При проведении внеклассного мероприятия «Озеленение пришкольного участка» учащимся предлагается, с помощью информационной системы, распланировать озеленение пришкольного участка, учитывая следующие параметры: механическую устойчивость, аварийность вида, ветроустойчивость, концепцию озеленения, критический возраст и экологические особенности видов древесных растений в условиях антропогенного воздействия. После чего сделать план участка со схематическим изображением деревьев разных видов.

\section{Результаты исследований}

Для выявления отношения школьников к обучению биологии с использованием информационной системы, учащимся было предложено анкетирование.

Вопросы анкеты:

1. Интересны ли вам занятия по биологии?
а) да;
б) скорее да, чем нет;

в) скорее нет, чем да;

г) нет.

2. Проводились ли раньше занятия с использованием каких-либо информационных систем?
а) да;
б) нет.

3. Как вы считаете, с помощью информационной системы новый материал усваивается лучше?
а) да;
б) нет;
в) не знаю.

4. Понравились ли вам проведенные занятия с использованием информационной системы?
а) да;
б) нет;
в) затрудняюсь ответить.

5. Полезны ли вам знания, полученные на подобных занятиях?
а) да;
б) нет;
в) не знаю.

6. Сможете ли вы применить полученные на занятиях знания в будущем?
а) да;
б) скорее да, чем нет;
в) скорее нет, чем да;
г) нет.

7. Сложно ли Вам было выполнять задания лабораторной работы?
а) да;
б) нет;
в) затрудняюсь ответить.

8. Сложно ли Вам было выполнять задания внеклассного мероприятия?
а) да;
б) нет;
в) затрудняюсь ответить.

В анкетировании приняло участие 20 учащихся. Результаты анкетирования представляют определенный интерес в связи с исследуемой проблемой. Из ответов на анкету учащихся стало известно, что дисциплина «Биология» вызывает интерес у $85 \%$ учащихся (рис. 5), а занятия с использованием информационной системы оценивают положительно 70\% учащихся (рис. 6).

Лабораторная работа и внеклассное мероприятие способствуют формированию у учащихся части следующих предметных компетенций [8]: 


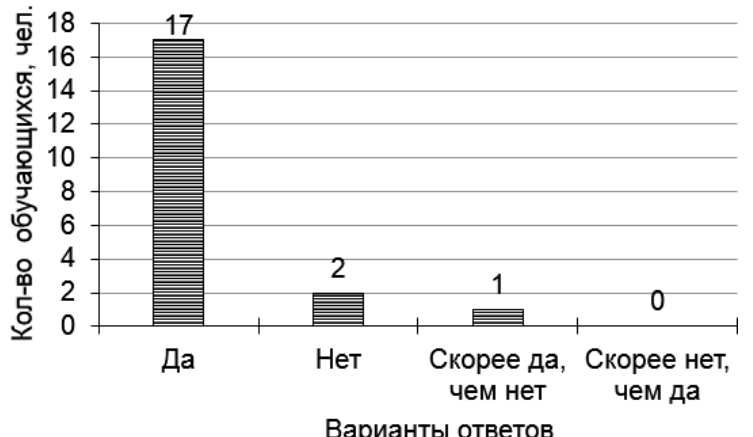

Рис. 5. Результаты ответов школьников на вопрос № 1 анкеты: «Интересны ли вам занятия по биологии?»

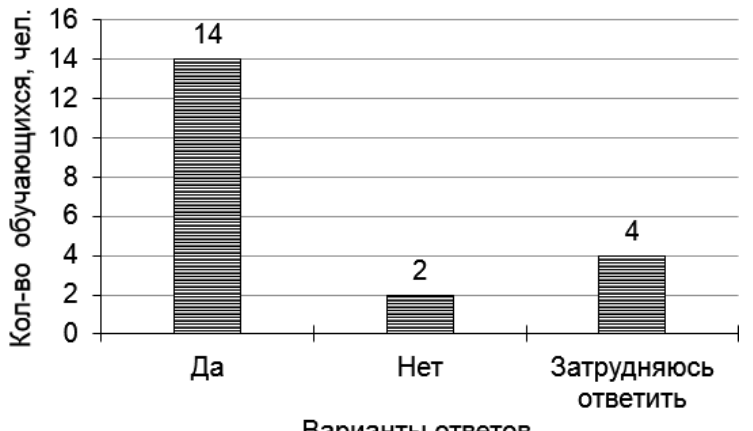

Варианты ответов

Рис. 6. Результаты ответов школьников на вопрос № 4 анкеты:

«Понравились ли вам проведенные занятия с использованием информационной системы?»

- соблюдение правил поведения в природе и участие в мероприятиях по ее охране;

- умение вести наблюдения в природе за сезонными явлениями, объектами живой природы;

- определение основных этапов работы, составление алгоритма для выполнения лабораторных и практических работ и умение корректировать или изменять алгоритм в зависимости от изменения условий;

- владение основными методами научного познания, используемыми при биологических исследованиях живых объектов и экосистем;

- сформированность умений объяснять результаты биологических экспериментов, решать элементарные биологические задачи;

- способность сравнивать биологические объекты между собой по заданным критериям, делать вы- воды и умозаключения на основе сравнения.

\section{Выводы}

Информационная система была внедрена и опробована в образовательном процессе. Были разработаны лабораторная работа «Определение видов древесных растений по плотности древесины» и внеклассное мероприятие на тему «Озеленение пришкольного участка» для 6 класса. По результатам исследований можно резюмировать, что применение, в процессе выполнения заданий, информационной системы по изучению механической устойчивости, аварийности и эколого-биологических особенностей основных видов древесных растений, используемых в озеленении города Донецка, может положительно сказаться на формировании у учащихся основных предметных компетенций.

ЛИТЕРАТУРА

1. Хуторской А.В. Современная дидактика: учеб. пособие. 2-е изд. М.: Высш. шк., 2007. 639 с.

2. Леднев В.С., Никандров Н.Д., Рыжаков М.В. Государственные образовательные стандарты в системе общего образования: теория и практика. М.: МПСи, 2002. 382 C.

3. Шадриков В.Д. Новая модель специалиста. Инновационная подготовка и компетентностный подход // Высшее образование сегодня. 2004 . № 8. C. 26-31.

4. Смирнова Н.3., Бережная 0.В. Компетентностный подход в биологическом образовании: учеб.-метод. пособие. Красноярск: Краснояр. гос. пед. ун-т им. В.П. Астафьева, 2012. 168 с.

5. Хуторской А.В. Компетентностный подход в обучении: науч.-метод. пособие. М.: Издательство «Эйдос», 2013. 73 с. 
6. Корниенко В.О., Калаев В.Н., Преображенский А.П., Львович И.Я. Информационная система для дистанционного обучения определению механической устойчивости, аварийности и эколого-биологических особенностей основных видов древесных растений, используемых в озеленении города Донецка // Моделирование, оптимизация и информационные технологии. 2020. № 8(4). С. 16-17. DOI: 10.26102/2310-6018/2020.31.4.035.

7. Корниенко В.О., Калаев В.Н., Преображенский А.П., Львович И.Я., Чопоров О.Н. Свидетельство РФ о государственной регистрации базы данных № 2020620885. Информационная обучающая система по механической устойчивости, аварийности и экологии основных видов-озеленителей города Донецка. Заявка № 2020620885 от 08.06.2020. Регистрация 30.06.2020 г.

8. Калашников Н.В., Артеменко Б.А. Педагогические условия формирования творческих естественнонаучных умений у школьников // Вестник Оренбургского государственного университета. 2015. № 2(177). С. 54-58.

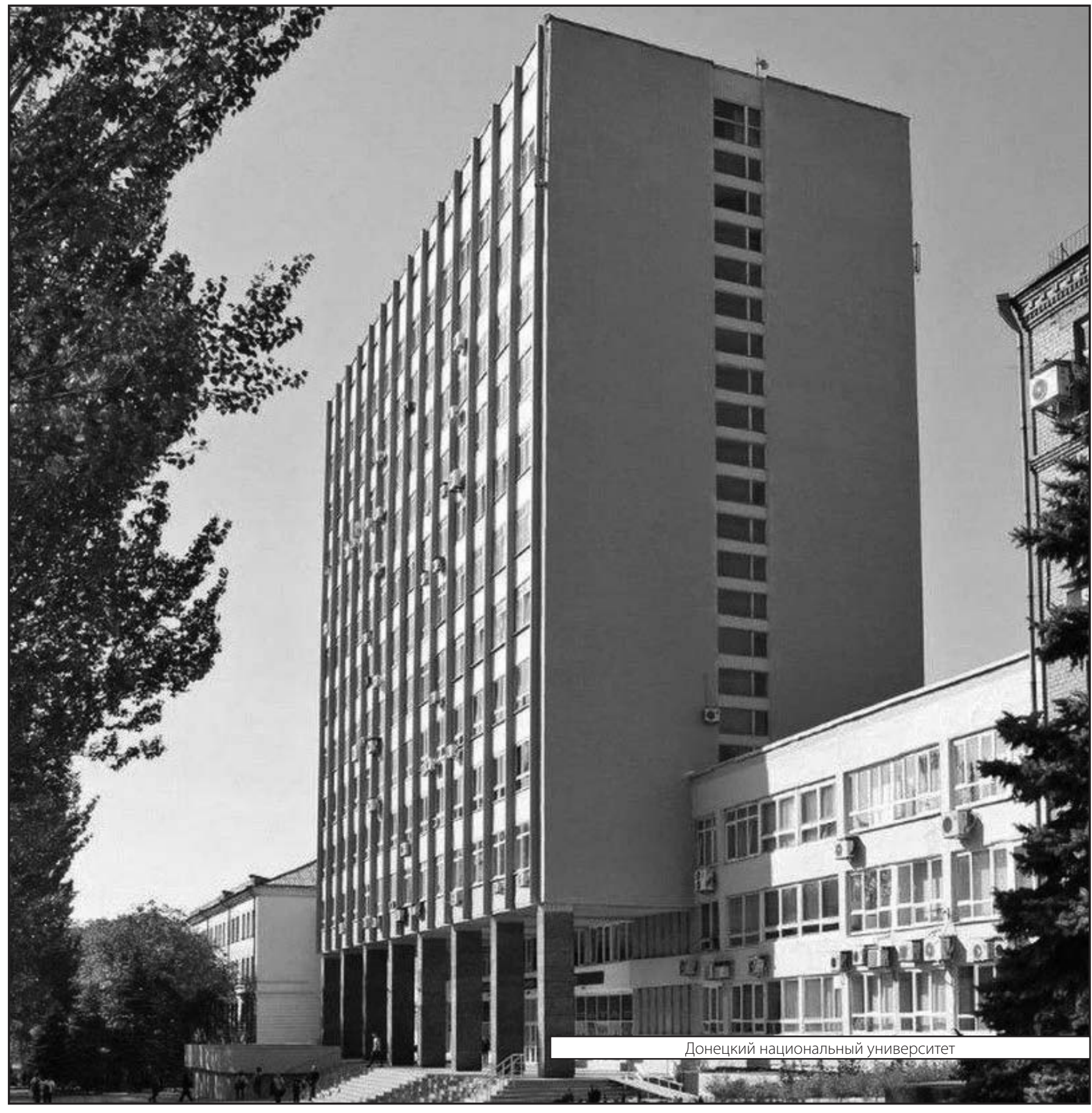

